\title{
Assigning the EPR Fine Structure Parameters of the Mn(II) Centers in Bacillus subtilis Oxalate Decarboxylase by Site-Directed Mutagenesis and DFT/MM Calculations
}

Pablo Campomanes, ${ }^{\dagger}$ Whitney F. Kellett, ${ }^{\ddagger}$ Lindsey M. Easthon, ${ }^{\S}$ Andrew Ozarowski, ${ }^{\perp}$ Karen N. Allen, ${ }^{\S}$ Alexander Angerhofer, "Ursula Rothlisberger, ${ }^{* \dagger}$ and Nigel G. J. Richards ${ }^{*}+$

${ }^{\dagger}$ Laboratory of Computational Chemistry and Biochemistry, Ecole Polytechnique Fédérale de Lausanne, CH-1015 Lausanne, Switzerland

${ }^{\ddagger}$ Department of Chemistry \& Chemical Biology, Indiana University Purdue University Indianapolis, Indianapolis, Indiana 46202, United States

${ }^{\S}$ Department of Chemistry, Boston University, Boston, Massachusetts 32310, United States

${ }^{\perp}$ National High Magnetic Field Laboratory, Florida State University, Tallahassee, Florida 32310, United States

"Department of Chemistry, University of Florida, Gainesville, Florida 32611, United States

\section{Supporting Information}

ABSTRACT: Oxalate decarboxylase (OxDC) catalyzes the Mn-dependent conversion of the oxalate monoanion into $\mathrm{CO}_{2}$ and formate. EPR-based strategies for investigating the catalytic mechanism of decarboxylation are complicated by the difficulty of assigning the signals associated with the two $\mathrm{Mn}$ (II) centers located in the $\mathrm{N}$ - and C-terminal cupin domains of the enzyme. We now report a mutational strategy that has established the assignment of EPR fine structure parameters to each of these $\mathrm{Mn}$ (II) centers at $\mathrm{pH}$ 8.5. These experimental findings are also used to assess the performance of a multistep strategy for calculating the zero-field splitting parameters of protein-bound $\mathrm{Mn}(\mathrm{II})$ ions. Despite the known sensitivity of calculated $D$ and $E$ values to the

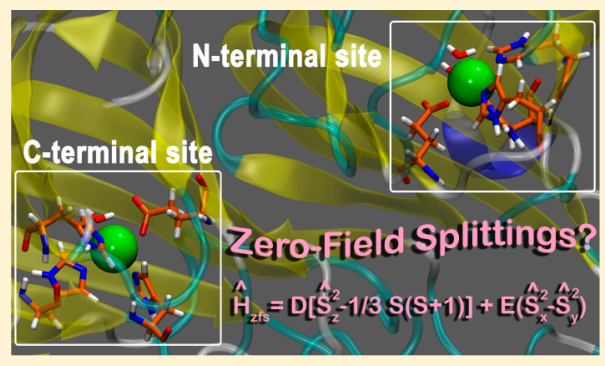
computational approach, we demonstrate that good estimates of these parameters can be obtained using cluster models taken from carefully optimized DFT/MM structures. Overall, our results provide new insights into the strengths and limitations of theoretical methods for understanding electronic properties of protein-bound $\mathrm{Mn}(\mathrm{II})$ ions, thereby setting the stage for future EPR studies on the electronic properties of the $\mathrm{Mn}(\mathrm{II})$ centers in $\mathrm{OxDC}$ and site-specific variants.

\section{INTRODUCTION}

Oxalate decarboxylase (OxDC) catalyzes the Mn-dependent conversion of oxalate monoanion into $\mathrm{CO}_{2}$ and formate. ${ }^{1}$ Although the enzyme appears to be found in many fungi and some bacteria, ${ }^{2}$ its biological function remains poorly understood. It has been shown, however, that $\mathrm{OxDC}$ is a constituent protein of the spore coat formed by Bacillus subtilis. ${ }^{3}$ The enzyme may also find utility in a number of biotechnological applications. ${ }^{4}$ Details of the mechanism by which OxDC mediates cleavage of the chemically unreactive $\mathrm{C}-\mathrm{C}$ bond in oxalate $^{5}$ remain to be clearly delineated. Heavy-atom isotope effect (IE) measurements ${ }^{6}$ and recent spin-trapping experiments ${ }^{7}$ are consistent with the hypothesis that reaction proceeds via heterolytic breakdown of a manganese-bound oxalate radical anion. ${ }^{8}$ In principle, the presence of $\mathrm{Mn}(\mathrm{II})$ in OxDC offers the opportunity to use EPR methods to explore the mechanistic role of the metal ion in catalysis. ${ }^{9}$ The situation is complicated, however, by the fact that the enzyme is composed of two cupin domains, each of which contains a $\mathrm{Mn}(\mathrm{II})$ ion in a similar coordination environment (Figure 1). ${ }^{10}$ As a result, even the high-field EPR spectra of the wild-type enzyme in buffer are complicated, and the effects of substrate binding and/or catalysis at a specific metal center are difficult to observe. It is therefore not surprising that two prior experimental studies have yielded conflicting assignments for the observed fine structure parameters of the two $\mathrm{Mn}$ (II) centers. $^{12}$

In principle, the application of modern theoretical methods to obtain estimates of the fine structure parameters $D$ and $E$ associated with each of the two $\mathrm{Mn}(\mathrm{II})$ centers in $\mathrm{OxDC}$ represents a means of resolving the discrepancy in assignments of the previous EPR studies. In practice, however, any accurate computation of fine structure parameters from first principles represents a significant challenge for modern quantum mechanical methods. This is especially true for high-spin $\mathrm{d}^{5}$ systems where the balance between the direct electronelectron magnetic dipole spin-spin (SS) interaction involving unpaired electrons and a second order term, arising from the spin-orbit coupling (SOC) of electronically excited states into

Received: August 6, 2013

Published: January 20, 2014 


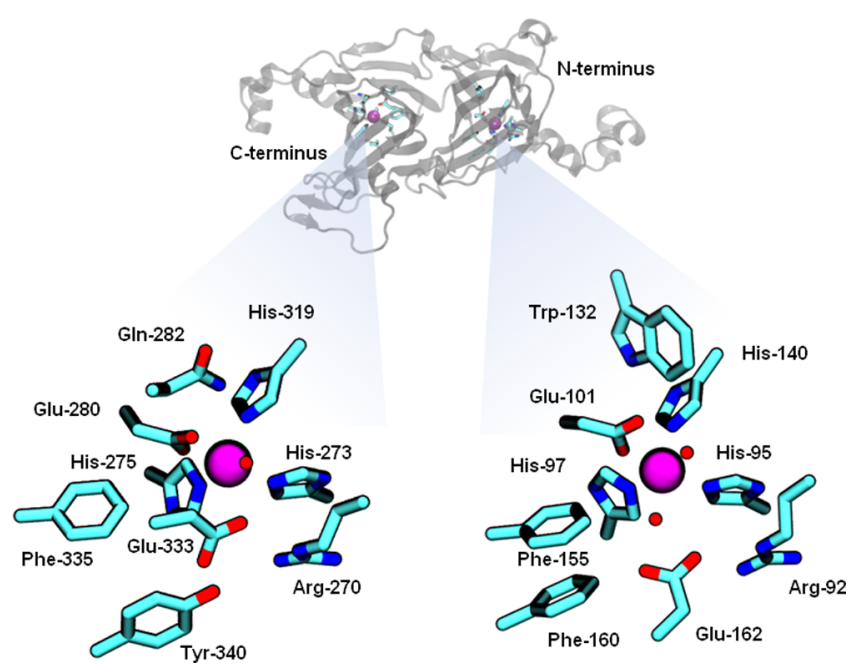

Figure 1. Representations of the $\mathrm{Mn}$ (II) binding sites in the Nterminal (right) and C-terminal (left) domains of Bacillus subtilis oxalate decarboxylase (1UW8). ${ }^{10 a}$ The location of the two Mn(II) centers in the monomer are indicated by the solid spheres in the ribbon drawing (top). Residue numbering is for the Bacillus subtilis enzyme. Color scheme: C, cyan; N, blue; O, red; Mn, purple. Metalbound water molecules are shown as red spheres. The figure was rendered using VMD. ${ }^{11}$

the ground state, gives rise to very small $D$ values ranging from nearly 0 to $1.5 \mathrm{~cm}^{-1}$ (corresponding to interaction energies on the order of $\left.0.004 \mathrm{kcal} \mathrm{mol}^{-1}\right)$. Estimates of fine structure parameters obtained using theoretical methods are therefore the difference between large contributions that have the same order of magnitude and opposing signs. Thus, even minor errors in calculating either of the SS or SOC contributions can significantly affect the accuracy of the final results. ${ }^{13}$ Efforts to employ density functional theory (DFT) for the accurate prediction of fine structure parameters are also complicated by the delicate balance between exchange and correlation contributions. Be that as it may, any demonstration that theoretical calculations are capable of yielding even qualitative insights into zero-field splittings would have wide application in the study of Mn-dependent enzymes and likely facilitate the interpretation of EPR spectra for multicenter systems, such as OxDC. ${ }^{9}$ To date, however, only one study has been published in which an integrated experimental/computational strategy was used to assign the fine structure parameters associated with $\mathrm{Mn}(\mathrm{II})$ ions bound to enolase. ${ }^{14}$

We now report a mutational strategy that has allowed us to establish the assignment of EPR fine structure parameters to each of the $\mathrm{Mn}$ (II) centers in wild-type OxDC, at least at high solution $\mathrm{pH}$. This work has also provided an opportunity to assess the performance of a combined DFT and DFT/MM computational strategy for calculating the zero-field splitting (zfs) parameters of the protein-bound $\mathrm{Mn}$ (II) ions in OxDC. Despite the known sensitivity of calculated $D$ and $E$ values to the computational approach, ${ }^{15}$ we demonstrate that good estimates of these parameters can be obtained using cluster models taken from carefully optimized DFT/MM structures. Overall, our findings not only confirm the assignments of Tabares et al. ${ }^{12 b}$ but also provide new insights into the strengths and limitations of theoretical methods for understanding electronic properties of protein-bound $\mathrm{Mn}$ (II) ions. This work also sets the stage for future EPR studies on the electronic properties of the $\mathrm{Mn}(\mathrm{II})$ centers in OxDC and sitespecific variants.

\section{RESULTS AND DISCUSSION}

High-Field (326.4 GHz) EPR Spectroscopy of WildType OxDC. $\mathrm{Mn}(\mathrm{II})$ is a $\mathrm{d}^{5}$ ion with a total spin quantum number of $S=5 / 2$. The transition between the $m_{S}=-5 / 2$ and $m_{\mathrm{S}}=-3 / 2$ electron spin manifolds is emphasized at temperatures below $4 \mathrm{~K}$ because of a large population difference according to Boltzmann statistics. ${ }^{16}$ Spectroscopically, this transition extends over a field range of $6(D+E) / g \mu_{\mathrm{B}}$, whereas that of the next higher energy transition between $m_{\mathrm{S}}=$ $-3 / 2$ and $m_{\mathrm{S}}=-1 / 2$, typically observed at temperatures above $5 \mathrm{~K}$, is only $3(D+E) / g \mu_{\mathrm{B}}{ }^{12 \mathrm{~b}}$ This is also true for the central transition between $m_{\mathrm{S}}=-1 / 2$ and $m_{\mathrm{S}}=+1 / 2$, although because these transitions are not directly affected by the fine structure to first order they are typically very sharp and intense. Importantly, frozen solution spectra observed at very low temperatures, at or below $4 \mathrm{~K}$, which feature the $m_{\mathrm{S}}=-5 / 2$ and $m_{\mathrm{S}}=-3 / 2$ transitions, allow the direct determination of not only $D$ and $E$ values but also the sign of $D .{ }^{12 \mathrm{~b}}$ Hence, the largest deviation of the powder spectrum from the center happens at low field with the main turning point at $-4|D| / g \mu_{\mathrm{B}}$ (measured from the center of the spectrum) for negative $D$ values, whereas the highest field component appears at $(2|D|+$ $6|E|) / g \mu_{\mathrm{B}}$ (Figure $\mathrm{S} 1$ in Supporting Information). The situation is reversed if $D$ has a positive sign. In the event that the rhombic component, $E$, has an appreciable magnitude, a splitting is observed on the side with the smaller deviation from the center, featuring signals at $(2|D|+6|E|) / g \mu_{\mathrm{B}}$ and $(2|D|-6 \mid$ $E \mathrm{l}) / g \mu_{\mathrm{B}}$. The sign of $E$ depends on how one defines the $x$ - and the $y$-axis of the fine structure tensor, and it can only be determined using single-crystal EPR spectroscopy. ${ }^{16}$

In studies of $\mathrm{OxDC}$ and its site-specific variants, our strategy of resolving the fine structure relies on observing the transitions between higher $m_{\mathrm{S}}$ states at the lowest possible temperature, which is between 2.5 and $3 \mathrm{~K}$ for our helium flow cryostat. These transitions are usually not very strong and require enzyme concentrations on the order of $20 \mathrm{mg} / \mathrm{mL}$ or higher to be reliably observed. We also routinely take EPR spectra at intermediate temperature $(40 \mathrm{~K})$ to distinguish between species exhibiting small and relatively large magnitudes of the fine structure parameters $D$ and $E$. The high-field EPR $(326.4 \mathrm{GHz})$ spectrum of wild-type (WT) $\mathrm{OxDC}$ at $\mathrm{pH} 8.5$ in frozen solution $(3 \mathrm{~K})$ clearly showed transitions associated with higher $m_{\mathrm{S}}$ states (Figure 2), enabling us to determine the fine structure values directly for at least one of the two $\mathrm{Mn}$ (II) species present in the enzyme. This $\mathrm{pH}$ was chosen because the X-ray crystal structure of WT OxDC, which was used in DFT and DFT/MM calculations, was obtained by crystallization at $\mathrm{pH}$ 8.5. We also note that observation of these weak transitions required the use of high enzyme concentrations $(27 \mathrm{mg} / \mathrm{mL})$, which could be achieved by modification of published purification protocols. $^{3,5,7}$ The intensity of the central $|+1 / 2\rangle$ $\leftrightarrow|-1 / 2\rangle$ sextet centered at $11658 \mathrm{mT}$ was greatly reduced due to Boltzmann population favoring the transition from the lowest level within the electron spin manifolds, $|-5 / 2\rangle \leftrightarrow \mid-3 /$ $2\rangle$. On its low-field side, a broad peak was visible, centered at around $11450 \mathrm{mT}$, and on the high-field side, there was a negative signal at $11760 \mathrm{mT}$. A poorly resolved shoulder was observed above $11800 \mathrm{mT}$ instead of the expected rhombic splitting, and because a fully axial fine structure tensor would yield a much narrower peak at high fields, this implied that the 


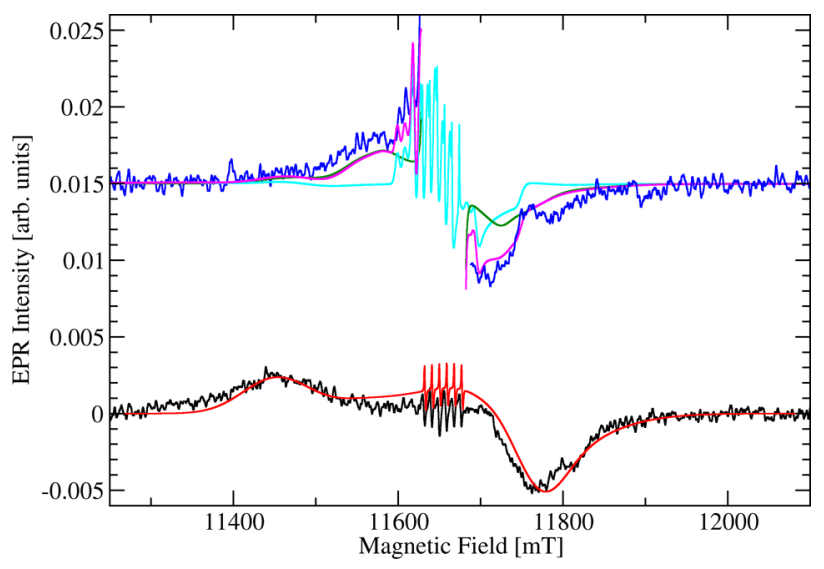

Figure 2. High-field (326.4 GHz) EPR spectra of WT OxDC taken at $3 \mathrm{~K}$ (black) and $40 \mathrm{~K}$ (blue) together with spectral simulations. Note that the central part of the spectrum at $40 \mathrm{~K}$ together with the corresponding spectral simulation of site I is removed for clarity. The enzyme $(27 \mathrm{mg} / \mathrm{mL})$ was dissolved in $50 \mathrm{mM}$ Tris buffer containing $500 \mathrm{mM} \mathrm{NaCl}, \mathrm{pH}$ 8.5. Lines from spectral simulations correspond to a single $\mathrm{Mn}(\mathrm{II})$ species (site I) with small zfs at $3 \mathrm{~K}$ (red) and $40 \mathrm{~K}$ (green) and a single $\mathrm{Mn}$ (II) species (site II) with very large zfs at $40 \mathrm{~K}$ (cyan). The sum of site I and site II simulations at $40 \mathrm{~K}$ is also shown (magenta). We note that site II does not contribute significantly to the spectral range visible. Unedited spectra and full sets of simulation parameters are provided elsewhere (Figures S2-S4 in Supporting Information).

fine structure parameter, $E$, had a broad distribution spanning essentially the whole range from zero to the maximum possible value of $|D| / 3$. By using a broad Gaussian distribution of $E$ centered around $200 \mathrm{MHz}$ with a half-width of $800 \mathrm{MHz}$, however, we were able to obtain a reasonable fit of the experimental spectrum (Figure 2). On the other hand, this approach was unable to recover the high-field shoulder present in the spectrum, implying that our experimental $E / D$ ratios (Table 1) have large errors associated with them, thereby making it difficult to draw hard conclusions from these values.

The spectrum at $40 \mathrm{~K}$ primarily showed the $|-3 / 2\rangle \leftrightarrow \mid-1 /$ 2) transitions on the low- and high-field side of a much stronger set of central $|+1 / 2\rangle \leftrightarrow|-1 / 2\rangle$ sextet lines relative to those seen at $3 \mathrm{~K}$ (Figure 2). These transitions were now located closer to the spectral center, and the $|-5 / 2\rangle \leftrightarrow|-3 / 2\rangle$ transitions were barely visible above the noise. Interestingly, there were three relatively sharp transitions visible on the lowfield side of the spectrum together with a broader feature on the high-field side as one would expect from a pentacoordinate species with $|D|$ of approximately $10 \mathrm{GHz}$. The appearance of overlapping spectra with differing zero-field splittings is consistent with the fact that $\mathrm{OxDC}$ contains two Mn binding sites. ${ }^{12}$ Simulations of the $40 \mathrm{~K}$ high-field EPR spectrum using the site I magnetic parameters extracted from the spectrum at 3 $\mathrm{K}$ together with a second species (site II) having very large fine structure $(\sim 10 \mathrm{GHz})$ gave a satisfactory global fit (Figure 2$)$ and yielded similar values for the fine structure parameters $D$ and $E$ (Table 1 ) to those reported previously. ${ }^{9 \mathrm{~b}}$ Site I has the smallest $|D|$ value and carries about $68 \%$ of the spectral weight. Unfortunately, the transitions associated with the second $\mathrm{Mn}$ (II) (site II) were not of sufficient intensity to allow direct experimental observation. Instead, we had to rely on the second-order effect of the fine structure on the central $m_{\mathrm{S}}=$ $-1 / 2$ to $m_{\mathrm{S}}=+1 / 2$ transitions, manifesting itself through broadenings and spectral splittings, which turn the sextet lines into a group of sharp lines at low field complemented by a broad Pake pattern on the high-field side (Figure S2 in Supporting Information). ${ }^{17}$ Given that these are second-order effects on the $+1 / 2 \leftrightarrow-1 / 2$ transitions, no information concerning the sign of $D$ could be obtained from our simulation. Values for the $g$-factor and hyperfine coupling constant $A$ with the ${ }^{55} \mathrm{Mn}$ nucleus were also obtained for the two $\mathrm{Mn}(\mathrm{II})$ sites in the enzyme (Table S1 in Supporting Information). Both of these sites are similar to ones reported by Tabares and co-workers (Table 1$),{ }^{12 b}$ with site II most probably corresponding to a pentacoordinate $\mathrm{Mn}(\mathrm{II})$ ion observed in the C-terminal domain of the enzyme by X-ray crystallography (Figure 1). ${ }^{10 a}$ Hence, site I is likely associated with a hexacoordinate $\mathrm{Mn}$ (II) bound within the $\mathrm{N}$-terminal domain of the enzyme.

Preparation and Kinetic Characterization of the W132F OxDC Variant. In order to confirm these assignments,

Table 1. Experimental and Calculated Fine Structure Parameters, D and E, of the N-Terminal and C-Terminal Mn(II) Binding Sites in WT OxDC and the W132F OxDC Variant

\begin{tabular}{|c|c|c|c|c|c|}
\hline \multirow[b]{2}{*}{ enzyme (active site) } & \multirow[b]{2}{*}{ type $(\mathrm{pH})$} & \multicolumn{2}{|c|}{ site I } & \multicolumn{2}{|c|}{ site II } \\
\hline & & $\mathrm{D}(\mathrm{MHz})$ & $E / D$ & $|D|(\mathrm{MHz})$ & $E / D$ \\
\hline WT OxDC & experimental (8.5) & -1350 & $0.15^{a}$ & 10430 & $0.20^{a}$ \\
\hline WT OxDC (Tabares et al.) $)^{12 b}$ & Experimental (8.8) & -1110 & 0.27 & 10730 & 0.16 \\
\hline WT OxDC (N-terminal) & DFT/MM-optimized & -1170 & 0.11 & $g$ & \\
\hline WT OxDC (C-terminal $)^{b}$ & DFT/MM-optimized & & & $4110^{h}$ & 0.22 \\
\hline WT OxDC (C-terminal) $)^{c}$ & DFT/MM-optimized & & & $4560^{h}$ & 0.14 \\
\hline $\mathrm{WT}$ OxDC $(\text { C-terminal })^{d}$ & DFT/MM-optimized & & & $7130^{h}$ & 0.13 \\
\hline W132F & experimental (8.5) & -1950 & $0.21^{a}$ & 10430 & 0.20 \\
\hline $\mathrm{W} 132 \mathrm{~F}(\mathrm{~N} \text {-terminal })^{e}$ & DFT/MM-optimized & -2100 & 0.23 & & \\
\hline W132F $(\mathrm{N} \text {-terminal })^{f}$ & DFT/MM-optimized & -1350 & 0.10 & & \\
\hline
\end{tabular}

${ }^{a}$ The error for $E / D$ values obtained in the present study is very large due to the broad distribution of $E$ values that had to be assumed in the simulations. These values are obtained from the center of a broad Gaussian distribution of $E$ (see text for more details). ${ }^{b}$ Cluster model containing water as the fifth ligand (Figure $7 \mathrm{~b}$ ). ${ }^{c}$ Cluster model containing hydroxide as the fifth ligand (Figure $7 \mathrm{c}$ ). ${ }^{d} \mathrm{Cluster}$ model containing hydroxide as the fifth ligand with a hydrogen bond to a solvent water (Figure 7d). ${ }^{e}$ Initial structure for QM/MM optimization based on the X-ray crystal structure of $\mathrm{Co}$ (II)-containing W132F OxDC variant. ${ }^{f}$ Initial structure for QM/MM optimization from in silico modification of the X-ray crystal structure of WT OxDC (1UW8). ${ }^{g}$ Not applicable. ${ }^{h}$ In the text, we report either the positive or the negative $D$ value as obtained by calculation. In this table, however, we give only absolute values for $D$ in the case of the C-terminal site because the sign of this parameter could not be experimentally determined. 
we decided to prepare a site-specific OxDC variant in which only the zfs parameters of the $\mathrm{N}$-terminal $\mathrm{Mn}$ (II) center would be perturbed, thereby leading to a shift in the $D$ and $E$ values associated with only one site. An analysis of the second sphere interactions revealed a hydrogen bonding interaction between the side chains of a conserved tryptophan (Trp-132) and the glutamate (Glu-101) coordinating $\mathrm{Mn}$ (II) in the N-terminal domain (Figure 3). We anticipated that removing this hydrogen

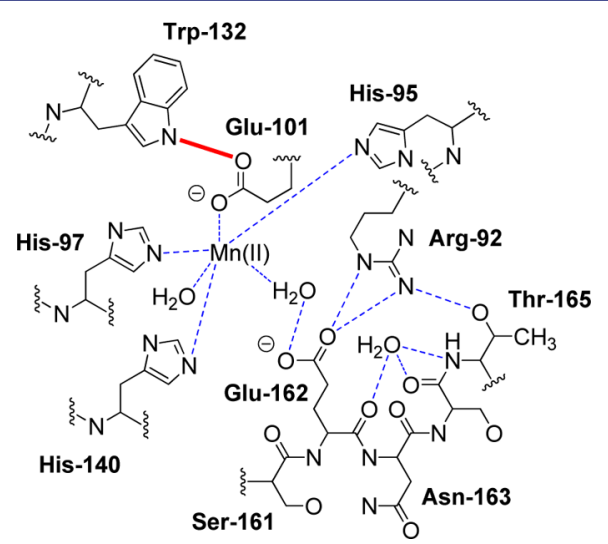

Figure 3. Schematic representation of hydrogen bonding interactions (dotted lines) involving residues in the Bacillus subtilis OxDC Nterminal $\mathrm{Mn}$ (II) binding site when the active site loop adopts a "closed" conformation. ${ }^{10 a}$ The Glu-101/Trp-132 hydrogen bond is shown in red. Reproduced with permission from ref 10a. Copyright 2004 American Society for Biochemistry and Molecular Biology.

bond would perturb the $\mathrm{Mn}(\mathrm{II}) / \mathrm{Glu}-101$ interaction, thereby affecting the zfs parameters, and so the $\mathrm{W} 132 \mathrm{~F}$ OxDC variant, in which Trp-132 is replaced by phenylalanine, was expressed and purified following our standard procedures. ${ }^{6}$ Metal analysis showed that the recombinant enzyme contained $1.6 \mathrm{Mn} /$ monomer. Steady-state kinetic analysis gave values of $63 \mathrm{~s}^{-1}$ and $50 \mathrm{mM}$ for $k_{\text {cat }}$ and $K_{\mathrm{m}}$, respectively (Figure S5 in Supporting Information), and so the W132F OxDC variant exhibited a 10 -fold lower catalytic efficiency $\left(k_{\text {cat }} / K_{\mathrm{m}}\right)$ than WT enzyme after normalizing for $\mathrm{Mn}(\mathrm{II})$ incorporation. However, the observations that (i) $k_{\text {cat }}$ was essentially unaffected by the site-specific mutation and (ii) $\mathrm{Mn}$ (II) incorporation was very similar in WT OxDC and the W132F OxDC variant supported the idea that the tertiary structure was not significantly affected by removal of the hydrogen bonding interaction.

X-ray Crystallography of the Co-Substituted W132F OxDC Variant. In order to ensure that there was indeed minimal impact on $\mathrm{Mn}$ (II) coordination and local protein structure as a result of replacing Trp-132 by phenylalanine, we sought to obtain an X-ray crystal structure of this OxDC variant. All efforts to grow diffraction quality crystals of the $\mathrm{Mn}$ (II)-substituted form of the $\mathrm{W} 132 \mathrm{~F}$ OxDC variant proved unsuccessful. We were able, however, to express and purify the $\mathrm{Co}(\mathrm{II})$-containing form of the mutant enzyme using conditions that had been developed in prior investigations into $\mathrm{OxDC}$ metal selectivity, ${ }^{8 a}$ and this material gave crystals that were suitable for structure determination. The X-ray crystal structure of Co-substituted W132F OxDC was solved using phases calculated by molecular replacement and refined to a resolution of $2.1 \AA$. The overall protein fold of the Co-containing W132F variant did not differ significantly from WT enzyme, and the two structures superimposed with an rmsd of only $0.26 \AA$. More importantly, perhaps, the phenyl ring in the $\mathrm{OxDC}$
W132F variant was positioned in an identical orientation to the indole side chain of Trp-132 within the N-terminal Mn(II) binding site (Figure 4). Comparison of the metal-ligand bond

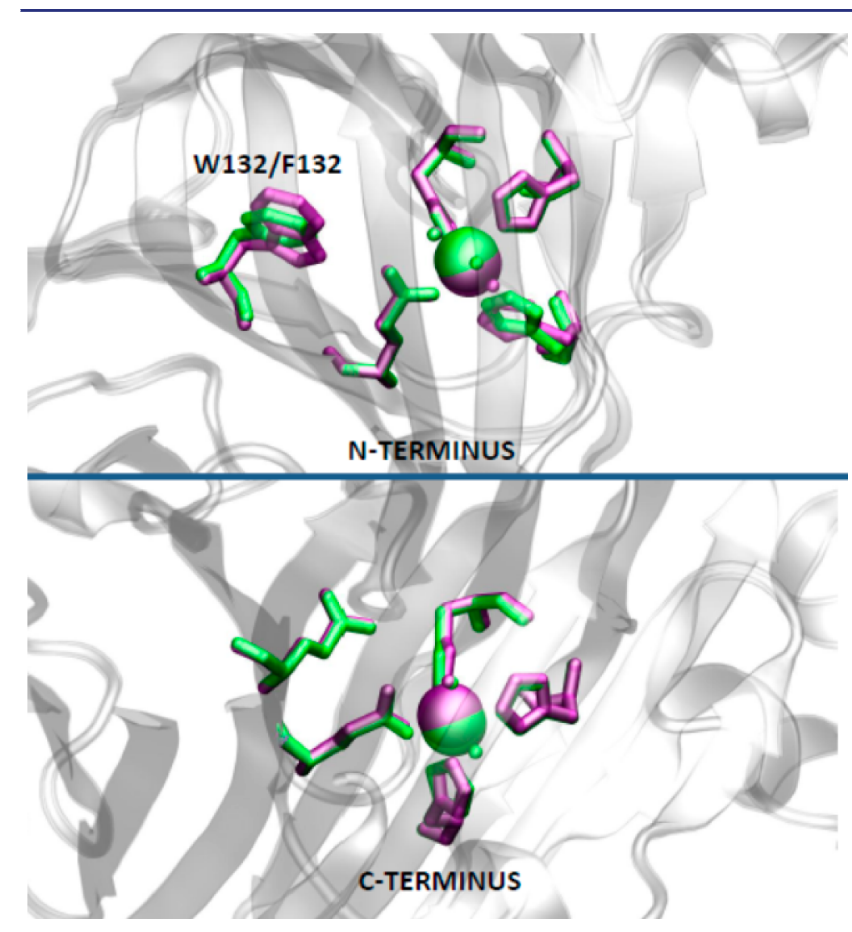

Figure 4. Schematic representation of the structural changes in the Nterminal (top) and C-terminal (bottom) metal centers resulting from replacement of Trp- 132 by phenylalanine. The figure was generated by superimposing the X-ray crystal structures of WT OxDC (1UW8) (purple) and the Co-containing W132F OxDC variant (green). The figure was rendered using VMD. ${ }^{11}$

distances in the Co-substituted form of the W132F OxDC variant and the Mn-containing WT enzyme also showed that they do not vary significantly in light of a $0.23 \AA$ coordinate error for the W132F structure (Figure S6 in Supporting Information). This similarity of $\mathrm{Co}$ (II) and $\mathrm{Mn}$ (II) metalligand bond lengths in $\mathrm{OxDC}$ is consistent with data in the Scripps Metalloprotein Database. ${ }^{18}$ For example, the average bond lengths for protein residues to $\mathrm{Mn}$ (II) ranges from 1.5 to $2.9 \AA$ with an average value of $2.20 \AA$. Co(II)-containing proteins have an average amino acid ligand bond length of 2.16 $\AA$ and range from 1.55 to 2.69 Å. Similarly, the bond distances for water ligands bound to $\mathrm{Mn}$ (II) and $\mathrm{Co}$ (II) range from 1.05 to $3.09 \AA$ (2.26 $\AA$ average) and 1.36-2.99 $\AA$ (2.26 Å average), respectively. Hence, at least in terms of metal-ligand bond distances and angles, $\mathrm{Co}(\mathrm{II})$ is a good mimic of $\mathrm{Mn}$ (II). As importantly, and despite the fact that Co-containing WT OxDC is catalytically inactive, ${ }^{8 a}$ the side chain carboxylate of the functionally important residue Glu-162, ${ }^{19}$ which is located on a mobile active site loop segment Ser $^{161}-\mathrm{Glu}^{162}-\mathrm{Asn}^{163}-\mathrm{Ser}^{164}$ (Bacillus subtilis numbering), ${ }^{10,20}$ undergoes only a small shift in position as a result of the site-specific mutation. On the other hand, we noted that the ring of His-97 had become "flipped" relative to its orientation in WT OxDC (Figure 5). Efforts to refine the structure of the variant enzyme with His-97 oriented in the same manner as observed in WT enzyme, however, merely resulted in reorientation of the ring to the original position in our initial structure for the W132F variant. The correct positioning of the His-97 side chain was also verified by 


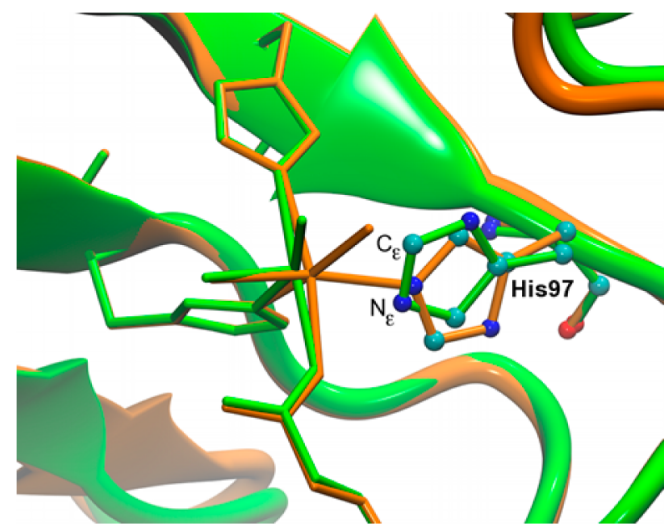

Figure 5. Superimposition of the $\mathrm{Mn}(\mathrm{II}) \mathrm{N}$-terminal binding sites observed in the X-ray crystal structures of $\mathrm{WT} \mathrm{OxDC}$ (orange) and the Co-containing W132F OxDC variant (green). Only the residues in the first coordination sphere around the metal are depicted as sticks. Figure rendered using VMD. ${ }^{11}$

a composite omit map (Figure S7 in Supporting Information). Importantly, the structure of the Co-substituted enzyme confirmed that replacement of Trp-132 by phenylalanine did not perturb the structure of the C-terminal Mn(II) binding site (Figure 4).

High-Field EPR (326.4 GHz) Spectroscopy of the W132F OxDC Variant. Given the kinetic and structural evidence that removal of the hydrogen bonding interaction between Glu-101 and Trp-132 was likely only to perturb the Nterminal Mn(II) center, we measured the high-field EPR (326.4 $\mathrm{GHz}$ ) spectrum of the $\mathrm{W} 132 \mathrm{~F} \mathrm{OxDC}$ variant at $\mathrm{pH} 8.5$ (Figure 6). The $\mathrm{W} 132 \mathrm{~F} \mathrm{OxDC}$ variant shows a broader spectrum of its transitions between higher $m_{S}$ states when compared with the WT enzyme. Hence, the low-field maximum now appeared at

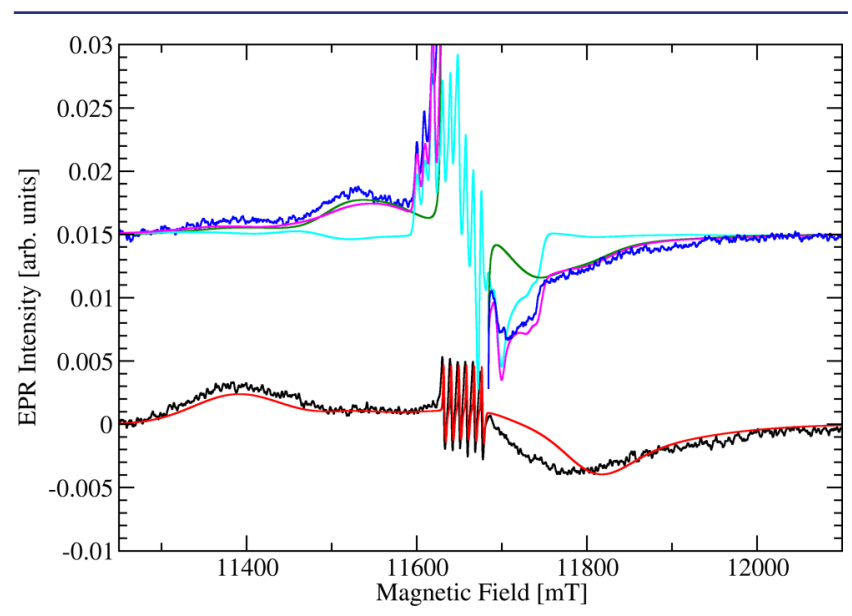

Figure 6. High-field (326.4 GHz) EPR spectra of the Mn-containing W132F OxDC variant taken at $3 \mathrm{~K}$ (black) and $40 \mathrm{~K}$ (blue) together with spectral simulations. Note that the central part of the spectrum at $40 \mathrm{~K}$ together with the corresponding spectral simulation of site I is removed for clarity. The enzyme $(40 \mathrm{mg} / \mathrm{mL})$ was dissolved in $50 \mathrm{mM}$ Tris buffer containing $500 \mathrm{mM} \mathrm{NaCl}, \mathrm{pH}$ 8.5. Lines from spectral simulations correspond to a single $\mathrm{Mn}(\mathrm{II})$ species (site I) with small zfs at $3 \mathrm{~K}$ (red) and $40 \mathrm{~K}$ (blue) and a single $\mathrm{Mn}$ (II) species (site II) with very large zfs at $40 \mathrm{~K}$ (cyan). The sum of site I and site II simulations at $40 \mathrm{~K}$ is also shown (magenta). We note that site II does not contribute significantly to the spectral range visible. Unedited spectra and full sets of simulation parameters are provided elsewhere (Figures S8-S10 in Supporting Information).
$11386 \mathrm{mT}$, and although the negative peak appeared to be centered at $11780 \mathrm{mT}$ (little shifted compared to WT enzyme), it was broader and reached out to higher fields (Figure 6). As perhaps expected from the negligible alterations to the structure of the C-terminal $\mathrm{Mn}(\mathrm{II})$ binding site in the Co-substituted W132F OxDC variant (Figure 4), the $40 \mathrm{~K} \mathrm{EPR} \mathrm{spectrum}$ showed evidence for a pentacoordinated $\mathrm{Mn}(\mathrm{II})$ species exhibiting the telltale sharp peaks at the low-field side and a Pake pattern at the near high-field side of the spectrum. As in our earlier studies of WT OxDC, we were able to simulate the observed transitions by assuming that only two Mn sites were present (Figure 6). Hence, assuming a single $\mathrm{Mn}$ (II) species having a negative $D$ value of $-1950 \mathrm{MHz}$ and a large Gaussian distribution of $E$ values centered around $400 \mathrm{MHz}$ with a halfwidth of $1200 \mathrm{MHz}$ gave a reasonable simulation of the lowfield side of the spectrum even though the broad feature on the high-field side could only be partially reproduced. An improved simulation could be obtained using a much broader nonGaussian spectral distribution of $D$ and $E$ in which $D$ and $E$ ranged between -1600 and $-2100 \mathrm{MHz}$ and between 100 $\mathrm{MHz}$ and the maximum value of $|D| / 3$, respectively (Figure $S 10$ in Supporting Information). Both simulations, however, provide clear experimental evidence for a significant increase in the magnitude of $D$ for one of the $\mathrm{Mn}$ (II) sites in the W132F OxDC variant when compared to WT enzyme. This spectroscopic behavior is therefore consistent with the hypothesis that removal of the Glu-101/Trp-132 hydrogen bond would impact the electronic structure of the $\mathrm{Mn}$ (II) ion bound in the N-terminal domain.

DFT and DFT/MM Calculations on WT OxDC. The ability of DFT and wave-function-based methodologies (widely and successfully used to model mononuclear inorganic complexes $^{21}$ ) to compute zfs values for a series of $\mathrm{Mn}$ (II) transition metal complexes has been evaluated. ${ }^{15}$ Perhaps, unsurprisingly, these studies revealed that the computed $\mathrm{zfs}$ values are highly dependent on molecular geometry. The availability of good structural and experimental zfs data for WT $\mathrm{OxDC}$ offered the opportunity to examine whether QM/MM methods for obtaining optimized active site geometries might yield structures that could (at the very least) be used to compute qualitatively correct estimates of the zfs parameters for protein-bound $\mathrm{Mn}(\mathrm{II})$ ions. Thus, an initial structure for performing QM/MM geometry optimizations was generated from classical MD simulations of WT OxDC solvated in water at physiological conditions. Although two X-ray structures have been reported for the enzyme, we used the one containing a pentacoordinate $\mathrm{Mn}$ (II) ion in the C-terminal domain (PDB ID: 1UW8) to obtain the initial set of atomic coordinates for all subsequent calculations on WT OxDC (Figure 1). After QM/ MM optimization of the metal centers in the initial enzyme, a set of cluster models were defined in which only $\mathrm{OH} / \mathrm{H}_{2} \mathrm{O}$ molecules in the active site cavity and the side chains of all the residues in the first coordination sphere around the metal were included (Figure 7).

These models were then used in calculations of the $\mathrm{zfs}$ parameters that employed the hybrid $\mathrm{B}^{2} \mathrm{LYP}^{22}$ functional in conjunction with triple- $\zeta$ (def2-TZVP) valence basis sets. Remarkably, excellent agreement was obtained in the prediction of both $D$ and $E / D$ values when $Q M / M M$-optimized geometries were used to obtain the atomic coordinates for these models, showing the importance of the surrounding residues in modulating the geometric features of the $\mathrm{OxDC}$ active sites (Table 1 and Table S2 in Supporting Information). 

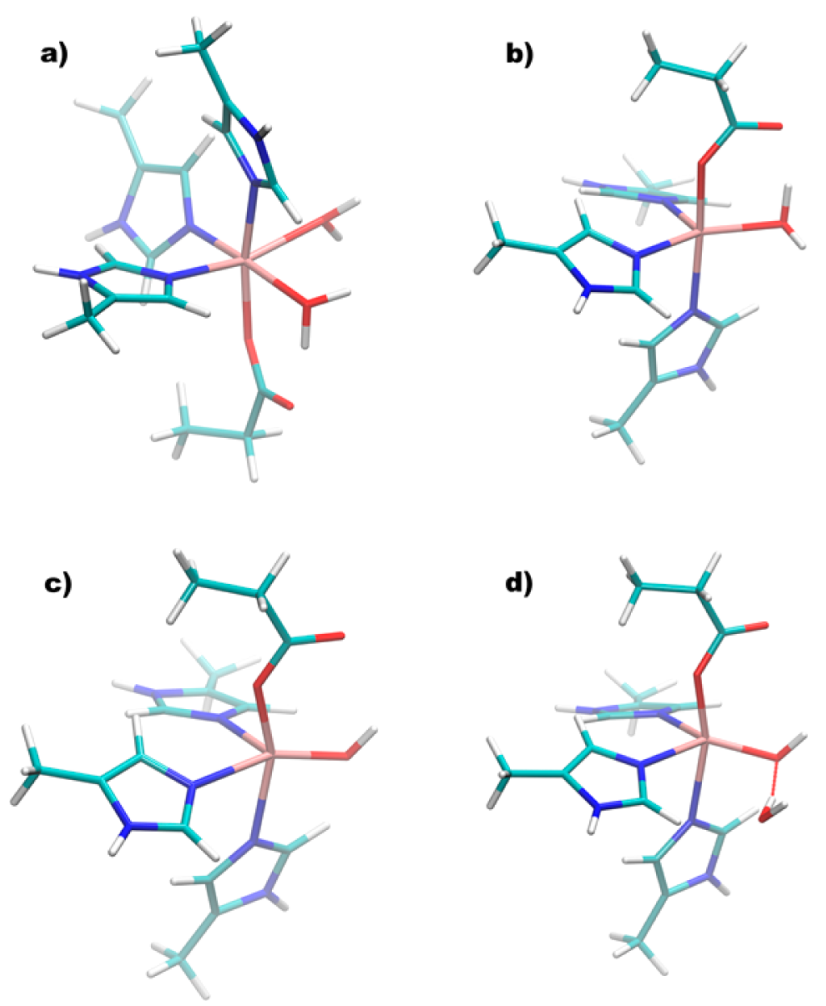

Figure 7. Cluster models taken from the DFT/MM-optimized structure of $\mathrm{WT} \mathrm{OxDC}$ that were used to calculate the $\mathrm{zfs}$ values of the bound $\mathrm{Mn}(\mathrm{II})$ ions in the (a) N-terminal and (b-d) C-terminal domains (see text for details). Color scheme: C, cyan; $\mathrm{H}$, white; $\mathrm{N}$, blue; oxygen, red; Mn, tan.

For example, the $D$ value of $-1170 \mathrm{MHz}$ computed for the $\mathrm{N}$ terminal Mn(II) cluster model (Figure 7a) was similar in both sign and absolute magnitude to that observed for site I $(D=$ $-1350 \mathrm{MHz}$, Table 1). Computing good estimates for the $D$ value associated with the C-terminal $\mathrm{Mn}$ (II) center required more effort. For example, an initial calculation on a cluster in which water was used as the fifth ligand (Figure $7 \mathrm{~b}$ ) gave a $D$ value of $-4110 \mathrm{MHz}$ from $\mathrm{B} 3 \mathrm{LYP} / \mathrm{def} 2-\mathrm{TZVP}$ calculations, which is considerably smaller than the observed $|D|$ value of $10430 \mathrm{MHz}$ (Table 1). Closer examination of the X-ray crystal structure, however, showed that the $\mathrm{Mn}-\mathrm{O}$ distance in the $\mathrm{C}$ terminal $\mathrm{Mn}(\mathrm{II})$ site was only $2.15 \AA$, whereas both $\mathrm{Mn}-\mathrm{O}$ distances for the metal center in the $\mathrm{N}$-terminal domain were significantly longer ( 2.31 and $2.33 \AA$ ). This observation thereby raised the possibility that the fifth ligand in the C-terminal site was a hydroxide ion rather than water. As a result, and especially given that the crystal structure (1UW8) had been obtained at $\mathrm{pH} 8.5$, we examined the effects of modeling the fifth ligand as a hydroxide ion. We therefore reoptimized the WT OxDC following the protocol previously outlined, except that hydroxide was bound to the metal in the C-terminal binding site, and created another cluster model of this $\mathrm{Mn}$ (II) center (Figure 7c). B3LYP/def2-TZVP calculations using this third model gave a computed $D$ value of $4560 \mathrm{MHz}$, which was a slight, albeit small, improvement. We noticed, however, that additional water molecules entered the C-terminal $\mathrm{Mn}$ (II) binding site during the initial set of classical $\mathrm{MD}$ simulations used in equilibrating the system. One of these waters formed a hydrogen bond to the $\mathrm{Mn}(\mathrm{II})$-bound hydroxide ligand after DFT/MM optimization. The B3LYP/def2-TZVP calculations were therefore repeated for a new cluster model containing this water molecule (Figure $7 \mathrm{~d}$ ), with the result that a $D$ value of $-7130 \mathrm{MHz}$ was obtained. This is in much better agreement with the experimentally observed value for the site II $\mathrm{Mn}$ (II) species. We also note that the calculated $E / D$ ratio for site I was similar to that obtained by analyzing the high-field EPR spectra, although any comparison of theoretical and our experimental $E / D$ values is devalued by the broad distribution of $E$ values needed in the spectral simulations. Despite this complication, our DFT-based computational strategy again supports the zfs assignments of Tabares et al. ${ }^{12 b}$

DFT and DFT/MM Calculations on the W132F OxDC Variant Built from the X-ray Crystal Structure of the Co(II)-Containing Enzyme. As an additional validation of our strategy for obtaining accurate geometries for $\mathrm{Mn}$ (II) binding sites in proteins that permit practically useful theoretical estimates of their corresponding zfs values, we constructed an optimized model of the $\mathrm{Mn}$ (II)-containing W132F OxDC variant based on the $2.1 \AA$ resolution X-ray crystal structure of the Co(II)-substituted enzyme. After "replacing" the Co(II) ions with $\mathrm{Mn}$ (II), our standard DFT/MM procedure was used to optimize the resulting structure. As discussed above, the Nterminal $\mathrm{Mn}$ (II) coordination environment in the initial configuration exhibited some unexpected features, including (i) rotation of the His-97 imidazole ring by about $180^{\circ}$ relative to its orientation in the X-ray crystal structure of WT OxDC, and (ii) almost identical $\mathrm{Mn}-\mathrm{N} \varepsilon(2.45 \AA)$ and $\mathrm{Mn}-\mathrm{C} \varepsilon(2.47$ $\AA$ ) distances for the interaction of the metal with His-97 (Figure 5).

In contrast, the final computational model of the $\mathrm{Mn}$ (II)containing W132F OxDC variant obtained using our standard protocol (equilibration using classical MD simulation followed by DFT/MM optimization) did not contain these unexpected structural features (Figure 8). Thus, the His-97 imidazole ring

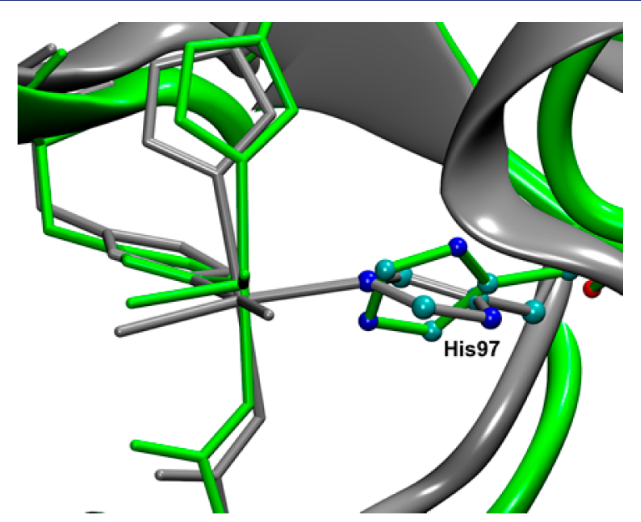

Figure 8. Superimposition of the $\mathrm{N}$-terminal $\mathrm{Mn}$ (II) binding sites present in the X-ray crystal structure of the Co-containing W132F OxDC variant (green) and the DFT/MM-optimized structure of the $\mathrm{Mn}(\mathrm{II})$-containing W132F OxDC variant (gray). Only the residues in the first coordination sphere around the metal are depicted as sticks. Figure rendered using VMD. ${ }^{11}$

underwent a rotation of about $70^{\circ}$ with respect to its orientation in the initial structure, and the $\mathrm{Mn}-\mathrm{N} \varepsilon(2.24 \AA)$ and $\mathrm{Mn}-\mathrm{C} \varepsilon(3.21 \AA)$ distances became appreciably different. Most importantly, however, B3LYP/def2-TZVP calculations on a cluster model of the $\mathrm{N}$-terminal $\mathrm{Mn}$ (II) site gave a $D$ value of $-2100 \mathrm{MHz}$ in very good agreement with experiment $(D=$ $-1950 \mathrm{MHz}$ ) (Table 1).

DFT and DFT/MM Calculations on the W132F OxDC Variant Built from the X-ray Crystal Structure of WT 
Table 2. Mn(II)-Ligand Internal Coordinates in the Cluster Models Used To Obtain the Computed Zero-Field Splitting Values

\begin{tabular}{|c|c|c|c|c|c|}
\hline internal coordinate $^{a}$ & $\mathrm{WT}_{\mathrm{OxDC}}^{b}$ & $\mathrm{WT} O \mathrm{ODC} C^{c}$ & $\mathrm{WT} \mathrm{OxDC}^{d}$ & W132F $(\text { model } 1)^{e}$ & W132F $\left(\right.$ model 2) ${ }^{f}$ \\
\hline $\mathrm{Mn}-\mathrm{O}\left(\mathrm{Glu}^{101}\right)^{g}$ & 2.12 & $h$ & & 2.15 & 2.11 \\
\hline $\mathrm{Mn}-\mathrm{N}\left(\mathrm{His}^{95}\right)$ & 2.29 & & & 2.24 & 2.27 \\
\hline $\mathrm{Mn}-\mathrm{N}\left(\mathrm{His}^{97}\right)$ & 2.31 & & & 2.24 & 2.31 \\
\hline $\mathrm{Mn}-\mathrm{N}\left(\mathrm{His}^{140}\right)$ & 2.36 & & & 2.36 & 2.35 \\
\hline $\mathrm{Mn}-\mathrm{O}$ (Wat1) & 2.33 & & & 2.39 & 2.36 \\
\hline $\mathrm{Mn}-\mathrm{O}(\mathrm{Wat} 2)$ & 2.21 & & & 2.28 & 2.19 \\
\hline$\left(\mathrm{Glu}^{101}\right) \mathrm{O}-\mathrm{Mn}-\mathrm{N}\left(\mathrm{His}^{95}\right)$ & 172.6 & & & 168.8 & 176.3 \\
\hline$\left(\mathrm{Glu}^{101}\right) \mathrm{O}-\mathrm{Mn}-\mathrm{N}\left(\mathrm{His}^{97}\right)$ & 89.3 & & & 87.3 & 87.2 \\
\hline$\left(\mathrm{Glu}^{101}\right) \mathrm{O}-\mathrm{Mn}-\mathrm{N}\left(\mathrm{His}^{140}\right)$ & 92.2 & & & 86.4 & 94.1 \\
\hline$\left(\mathrm{Glu}^{101}\right) \mathrm{O}-\mathrm{Mn}-\mathrm{O}($ Wat 1$)$ & 100.9 & & & 98.5 & 99.0 \\
\hline$\left(\mathrm{Glu}^{101}\right) \mathrm{O}-\mathrm{Mn}-\mathrm{O}($ Wat2 $)$ & 88.5 & & & 90.4 & 90.5 \\
\hline$\left(\mathrm{His}^{95}\right) \mathrm{N}-\mathrm{Mn}-\mathrm{N}\left(\mathrm{His}^{97}\right)$ & 95.8 & & & 92.8 & 95.2 \\
\hline$\left(\mathrm{His}^{95}\right) \mathrm{N}-\mathrm{Mn}-\mathrm{N}\left(\mathrm{His}^{140}\right)$ & 82.4 & & & 86.7 & 83.1 \\
\hline$\left(\mathrm{His}^{95}\right) \mathrm{N}-\mathrm{Mn}-\mathrm{O}($ Wat 1$)$ & 85.0 & & & 92.6 & 84.0 \\
\hline$\left(\mathrm{His}^{95}\right) \mathrm{N}-\mathrm{Mn}-\mathrm{O}($ Wat 2$)$ & 86.7 & & & 92.0 & 87.2 \\
\hline$\left(\mathrm{His}^{97}\right) \mathrm{N}-\mathrm{Mn}-\mathrm{N}\left(\mathrm{His}^{140}\right)$ & 90.4 & & & 103.2 & 90.6 \\
\hline$\left(\mathrm{His}^{97}\right) \mathrm{N}-\mathrm{Mn}-\mathrm{O}(\mathrm{Wat} 1)$ & 85.2 & & & 86.1 & 84.3 \\
\hline$\left(\mathrm{His}^{97}\right) \mathrm{N}-\mathrm{Mn}-\mathrm{O}($ Wat2 $)$ & 175.4 & & & 166.4 & 175.6 \\
\hline$\left(\mathrm{His}^{140}\right) \mathrm{N}-\mathrm{Mn}-\mathrm{O}$ (Wat1) & 166.2 & & & 169.7 & 165.6 \\
\hline$\left(\mathrm{His}^{140}\right) \mathrm{N}-\mathrm{Mn}-\mathrm{O}($ Wat2 $)$ & 93.8 & & & 90.0 & 93.3 \\
\hline (Wat1)O-Mn-O(Wat2) & 91.2 & & & 81.1 & 92.4 \\
\hline $\mathrm{Mn}-\mathrm{O}\left(\mathrm{Glu}^{280}\right)$ & 2.05 & 2.07 & 2.10 & & \\
\hline $\mathrm{Mn}-\mathrm{N}\left(\mathrm{His}^{273}\right)$ & 2.46 & 2.27 & 2.33 & & \\
\hline $\mathrm{Mn}-\mathrm{N}\left(\mathrm{His}^{275}\right)$ & 2.30 & 2.25 & 2.43 & & \\
\hline $\mathrm{Mn}-\mathrm{N}\left(\mathrm{His}^{319}\right)$ & 2.41 & 2.25 & 2.33 & & \\
\hline $\mathrm{Mn}-\mathrm{O}(\mathrm{H})$ & 2.00 & $2.19^{i}$ & 1.98 & & \\
\hline$\left(\mathrm{Glu}^{280}\right) \mathrm{O}-\mathrm{Mn}-\mathrm{N}\left(\mathrm{His}^{273}\right)$ & 163.6 & 173.2 & 157.0 & & \\
\hline$\left(\mathrm{Glu}^{280}\right) \mathrm{O}-\mathrm{Mn}-\mathrm{N}\left(\mathrm{His}^{275}\right)$ & 81.1 & 85.0 & 75.8 & & \\
\hline$\left(\mathrm{Glu}^{280}\right) \mathrm{O}-\mathrm{Mn}-\mathrm{N}\left(\mathrm{His}^{319}\right)$ & 98.5 & 98.9 & 97.0 & & \\
\hline$\left(\mathrm{Glu}^{280}\right) \mathrm{O}-\mathrm{Mn}-\mathrm{O}(\mathrm{H})$ & 116.0 & 90.2 & 116.8 & & \\
\hline$\left(\mathrm{His}^{273}\right) \mathrm{N}-\mathrm{Mn}-\mathrm{N}\left(\mathrm{His}^{275}\right)$ & 83.7 & 88.5 & 81.5 & & \\
\hline$\left(\mathrm{His}^{273}\right) \mathrm{N}-\mathrm{Mn}-\mathrm{N}\left(\mathrm{His}^{319}\right)$ & 78.2 & 85.1 & 82.6 & & \\
\hline$\left(\mathrm{His}^{273}\right) \mathrm{N}-\mathrm{Mn}-\mathrm{O}(\mathrm{H})$ & 79.7 & 94.3 & 86.0 & & \\
\hline$\left(\mathrm{His}^{275}\right) \mathrm{N}-\mathrm{Mn}-\mathrm{N}\left(\mathrm{His}^{319}\right)$ & 100.2 & 109.2 & 98.8 & & \\
\hline$\left(\mathrm{His}^{275}\right) \mathrm{N}-\mathrm{Mn}-\mathrm{O}(\mathrm{H})$ & 139.7 & 148.5 & 158.5 & & \\
\hline$\left(\mathrm{His}^{319}\right) \mathrm{O}-\mathrm{Mn}-\mathrm{O}(\mathrm{H})$ & 111.7 & 102.3 & 96.7 & & \\
\hline
\end{tabular}

${ }^{a}$ Bond lengths $(\AA)$ and angles $\left({ }^{\circ}\right) .{ }^{b} \mathrm{QM} / \mathrm{MM}$-optimized structure with the bound hydroxide in the C-terminal Mn(II) center forming a hydrogen bond to a water molecule. This structure was obtained from the X-ray crystal structure of WT OxDC (1UW8) (Figure 7a,d). ${ }^{c} \mathrm{QM} / \mathrm{MM}-\mathrm{optimized}$ structure with water bound to the $\mathrm{C}$-terminal $\mathrm{Mn}(\mathrm{II})$ center based on the X-ray crystal structure (1UW8) (Figure $7 \mathrm{~b}$ ). ${ }^{d} \mathrm{QM} / \mathrm{MM}$-optimized structure with hydroxide bound to the C-terminal $\mathrm{Mn}$ (II) center based on the X-ray crystal structure (1UW8) (Figure 7c). ${ }^{e} \mathrm{QM} / \mathrm{MM}$-optimized structure obtained from the X-ray crystal structure of the Co(II)-containing W132F OxDC variant. ${ }^{f} \mathrm{QM} / \mathrm{MM}$-optimized structure obtained from in silico substitution of the X-ray crystal structure of WT OxDC (1UW8). ${ }^{g}$ Bacillus subtilis residue numbering. ${ }^{h}$ Not applicable. ${ }^{i} \mathrm{Mn}(\mathrm{II})$-bound water.

OxDC. We also assessed the ability of our computational protocol to be employed in a predictive manner by calculating the $\mathrm{Mn}(\mathrm{II})$ zfs values for the $\mathrm{N}$-terminal metal center in a model of the W132F OxDC variant prepared by in silico mutation. Hence, the X-ray crystal structure of WT OxDC (1UW8) was computationally modified so that Trp-132 was replaced by a phenylalanine residue. The resulting model was then equilibrated and optimized using our standard protocol to give a final structure in which the hydrogen bond between the Glu-101 side chain, and the closest $\mathrm{Mn}$ (II)-bound water became slightly shorter as a consequence of removing the interaction between Glu-101/Trp-132 (Table 2). Changes in other metal-ligand bond distances were also observed together with slight changes in the locations of the side chains of some nearby residues. Once again, B3LYP/def2-TZVP calculations were performed on a cluster model of the N-terminal $\mathrm{Mn}$ (II) site corresponding to that used for calculations on WT OxDC (Figure 7a). The computed $D$ value of $-1350 \mathrm{MHz}$ (Table 1) shows that this optimized model structure captures the increased magnitude of $D$ that is experimentally observed on removal of the Glu-101/Trp-132 hydrogen bond. On the other hand, the absolute value is smaller than that computed from a model based on the X-ray crystal structure of the Co(II)containing W132F OxDC variant (Table 1). Given that superimposition of the two cluster models used to compute the zfs parameters for the $\mathrm{N}$-terminal $\mathrm{Mn}$ (II) site in the W132F OxDC variant showed all metal-ligand distances to be similar in both structures, the difference in the calculated $D$ values likely arises from altered orientations of the imidazole rings of His-97 and (to a smaller extent) His-95 (Figure 9). Taken overall, these results suggest that the computational strategy described in this paper yields reliable structural information and, as a consequence, very good estimates of zfs values for protein-bound $\mathrm{Mn}$ (II) centers. Importantly, our approach opens the possibility of computing fine structure parameters 


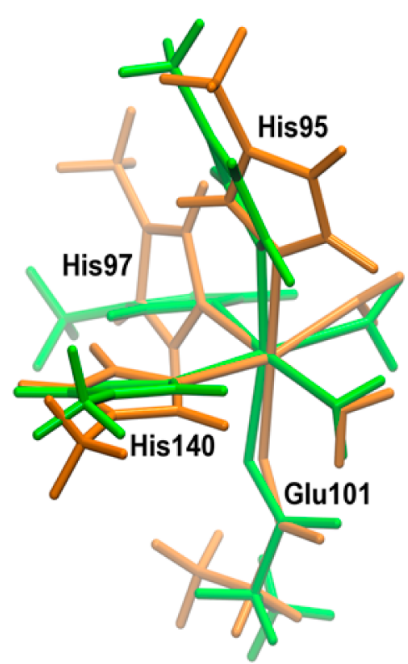

Figure 9. Superimposition of the cluster models used to calculate the zfs parameters of the $\mathrm{Mn}(\mathrm{II}) \mathrm{N}$-terminal binding site in the W132F OxDC variant. Color scheme: green, initial structure based on the $\mathrm{X}$ ray crystal structure of the $\mathrm{Co}$ (II)-containing variant; orange, initial structure derived from the X-ray crystal structure of WT enzyme (in silico substitution). Figure rendered using VMD. ${ }^{11}$

in biomolecular systems for which only lower-resolution crystal structures are available.

\section{CONCLUSIONS}

In addition to resolving the question of $\mathrm{Mn}$ (II) assignments for OxDC, this study provides further evidence for the utility of advanced quantum mechanical calculations in probing the electronic structure of protein-bound metal centers. To date, there have been few such calculations, in part because previous efforts to compute $\mathrm{zfs}$ parameters on a series of $\mathrm{Mn}(\mathrm{II})$ containing complexes gave large differences between theoretically predicted and experimentally measured values. These discrepancies can be attributed to the high sensitivity of the $\mathrm{zfs}$ parameters to the geometrical features of the structures used for the calculations. It is also true that the requirement that $\mathrm{zfs}$ parameters reflect only small energy differences places considerable demands on the computational methods used to obtain them, and only a qualitative agreement giving rise to correct trends can be expected in general. On this point, we note that the overestimated $D$ values found in efforts to compute the $\mathrm{zfs}$ parameters for the $\mathrm{Mn}$ (II) ions bound to enolase $^{14}$ were attributed both to the high sensitivity of the calculated values to the molecular geometries employed and the use of DFT calculations instead of correlated ab initio methods. However, some of the limitations associated with the use of DFT methodologies might be overcome by employing the more recently developed coupled-perturbed spin-orbit coupling (CP-SOC) formalism (as used here) instead of the Pederson and Khanna (PK) approach used in the previous work on enolase-bound $\mathrm{Mn}$ (II) ions, provided that the direct spin-spin interaction is properly included in the treatment. In particular, systematic investigation of the ability of coupledperturbed DFT methodologies to estimate $\mathrm{zfs}$ parameters in $\mathrm{Mn}$ (II) transition metal complexes ${ }^{15}$ also showed that reliable results could be obtained using a hybrid DFT functional (B3LYP) if accurate geometries were employed.

The theoretical results reported herein, however, demonstrate that the use of a strategy based on computation of zfs parameters at the DFT theory level for cluster models obtained from QM/MM-optimized structures has some value, especially if high-quality X-ray structures are available for the protein, or site-specific variant, of interest. Indeed, the reorientation of the His-97 side chain observed upon the application of our computational protocol was likely an essential element in obtaining good agreement between the calculated and experimentally observed zfs parameters. Our results also show that QM/MM-optimized models of variant structures can also yield qualitatively correct changes in computed $\mathrm{zfs}$ values, especially when the site-specific mutation does not introduce large structural changes in the metal ion environment. Presumably this reflects the ability of carefully equilibrated $\mathrm{QM} / \mathrm{MM}$ structures to capture the critical metal-ligand interactions, such as metal-ligand distances and coordination geometries, needed to obtain good estimates of zfs parameters. Although additional systematic computational investigations on the problem of computing zfs values are clearly needed, our findings set the scene for theoretical studies aimed at delineating the effect of active site modifications on the electronic structure of the metal centers in $\mathrm{OxDC}$ and, perhaps, other Mn-dependent enzymes.

\section{EXPERIMENTAL SECTION}

Expression, Purification, and Kinetic Characterization of WT OxDC and the Mn(II)- and Co(II)-Containing W132F OxDC Variants. Unless otherwise stated, all chemicals were purchased in the highest purity from Sigma (St. Louis, MO) or Fischer Scientific (Pittsburgh, PA). Nickel-nitrilotriacetic acid agarose (Ni-NTA) was obtained from Qiagen (Germantown, MD). Protein concentrations were determined using the Bradford assay (Pierce, Rockford, IL). ${ }^{23}$ All DNA primers were obtained from Integrated DNA Technologies, Inc. (Coralville, IA), and DNA sequencing was performed by the core facility in the Interdisciplinary Center for Biotechnology Research at the University of Florida. ICP-MS determinations of metal content were performed at the University of Georgia Center for Applied Isotope Studies Chemical Analysis Laboratory (Athens, GA). The gene encoding the $\mathrm{W} 132 \mathrm{~F}$ OxDC variant was constructed by overlap extension (see Supporting Information). ${ }^{24}$ The recombinant His $_{6}$ tagged $\mathrm{Mn}(\mathrm{II})$-substituted $\mathrm{W} 132 \mathrm{~F}$ OxDC variant was expressed and purified following published procedures, ${ }^{8 a}$ except that expression was induced in the presence of $5 \mathrm{mM} \mathrm{MnCl} 2$ after heat shocking the bacteria for $12 \mathrm{~min}$ at $42{ }^{\circ} \mathrm{C}$ with constant agitation. After the addition of IPTG, the cultures were incubated at $37{ }^{\circ} \mathrm{C}$ for $4 \mathrm{~h}$ before being harvested by centrifugation at $2000 \mathrm{~g}$ for $20 \mathrm{~min}\left(4{ }^{\circ} \mathrm{C}\right)$. After sonication in lysis buffer, the resulting supernatant was centrifuged at $20000 \mathrm{~g}$ for $20 \mathrm{~min}\left(4^{\circ} \mathrm{C}\right)$ before the enzyme was purified from the cleared lysate by metal affinity chromatography on a Ni-NTA column. The eluted protein was then subjected to dialysis at $4{ }^{\circ} \mathrm{C}$ to give a solution in $50 \mathrm{mM}$ Tris buffer containing $500 \mathrm{mM} \mathrm{NaCl}, \mathrm{pH} 8.5$. Samples used for EPR analysis were incubated with Chelex resin before being concentrated to $27 \mathrm{mg} / \mathrm{mL}$ using an Amicon Centriprep YM-30 filter unit from Millipore (Billerica, MA). The catalytic properties of the $\mathrm{His}_{6}$-tagged $\mathrm{Mn}$ (II)-containing W132F OxDC variant were determined by measuring formate production using an end-point assay as described elsewhere. ${ }^{. a}$ Measurements were made at specific substrate and enzyme concentrations in triplicate, and the data were analyzed to obtain the values of $V$ and $V / K$ by standard computerbased methods. ${ }^{25} \mathrm{His}_{6}$-tagged $\mathrm{Co}(\mathrm{II})$-containing W132F OxDC was expressed as described previously with the addition of $2 \mathrm{mM} \mathrm{CoCl}_{2}$ after heat shocking the cells at $42^{\circ} \mathrm{C}$ for $18 \mathrm{~min}$. Cells were lysed using a microfluidizer, and the mixture was clarified by centrifugation at 38 $000 \mathrm{~g}$ for $30 \mathrm{~min}$. The soluble protein was then purified using a Talon cobalt column. The eluate was dialyzed overnight in the storage buffer $(50 \mathrm{mM}$ Tris- $\mathrm{HCl}, \mathrm{pH} 8.5$, and $500 \mathrm{M} \mathrm{NaCl}$ ), and the protein was then further purified on a $320 \mathrm{~mL}$ sephacryl S-100 gel filtration column. 
Table 3. Crystallographic Data and Refinement Statistics ${ }^{a}$

\begin{tabular}{ll}
\multicolumn{2}{c}{ data Collection } \\
resolution (highest resolution shell) $(\AA)$ & $47.39-2.095(2.17-2.095)$ \\
X-ray source & X25, NSLS \\
wavelength $(\AA)$ & 0.979 \\
space group & $R 3_{2}$ \\
cell dimension $(\AA)$ & $a=b=156.97, c=330.47$ \\
reflections observed (unique) & $177937(91647)$ \\
completeness $(\%)$ & $99.7(100)$ \\
$R_{\text {merge }}(\%)^{b}$ & $14.7(29.2)$ \\
$I / \sigma(I)$ & $3.3(2.56)$ \\
redundancy & $19.1(13.2)$
\end{tabular}

refinement
protein residues/water molecules per asu
other ligands per asu
reflections (work/free)
$R_{\text {work }} / R_{\text {free }}(\%)$
resolution $(\AA)$
average $\mathrm{B}$-factor $\left(\AA^{2}\right)$
protein $\left(\AA^{2}\right)$
Co $(\mathrm{II})\left(\AA^{2}\right)$
water $\left(\AA^{2}\right)$
$\mathrm{rmsd}^{c}$ bond lengths $(\AA)$
$\operatorname{rmsd}^{2}$ bond angles $\left({ }^{\circ}\right)$
$1508 / 1228$
8
$91562 / 1997$
$19.6 / 22.7$
$49.06-2.09$
23.15
17.55
21.02
0.008
1.113

${ }^{a}$ Data for the highest resolution shell is in parentheses. ${ }^{b} R_{\text {merge }}=\sum_{h k l} \sum_{i}\left|I_{h k l, i}-\left\langle I_{h k l}\right\rangle I\right| / \sum_{h k l} \sum_{i}\left|I_{h k l, i}\right|$, where $\left\langle I_{h k l}\right\rangle$ is the mean intensity of the multiple $I_{h k l, i}$ observations for symmetry-related reflections. ${ }^{c}$ Root-mean-square deviation.

X-ray Crystal Structure of the Co-Substituted W132F OxDC Variant. Purified $\mathrm{Co}(\mathrm{II})$-containing $\mathrm{W} 132 \mathrm{~F}$ OxDC was concentrated to $5 \mathrm{mg} / \mathrm{mL}$ in $100 \mathrm{mM}$ Tris-HCl, $\mathrm{pH} 8.5$, containing $500 \mathrm{mM} \mathrm{NaCl}$. Crystals were obtained by the vapor diffusion method with hanging drop geometry by mixing protein $(2 \mu \mathrm{L})$ and well solution $(2 \mu \mathrm{L})$. The well solution contained $100 \mathrm{mM}$ Tris- $\mathrm{HCl}, \mathrm{pH} 8.5,2 \mathrm{M} \mathrm{NaCl}$ and $10 \%$ PEG 6000. Crystals, which were rectangular prisms $(0.3 \times 0.2 \times 0.2$ $\mathrm{mm}$ ), appeared in approximately 2 months at $17{ }^{\circ} \mathrm{C}$ and were cryoprotected in well solution containing $25 \%$ glycerol and flash frozen in liquid nitrogen. The Co(II)-substituted W132F variant crystallized in space group $R 3_{2}$ with unit cell dimensions $a=b=156.973 \AA$ and $c=$ $330.473 \AA$. Data were collected to $1.9 \AA$ resolution at the National Synchrotron Light Source (NSLS), Brookhaven National Laboratory (Upton, NY), at beamline X25 equipped with a Pilatus 6M detector (Table 3). Phasing was achieved by molecular replacement ${ }^{26}$ (PhaserMR in the Phenix software suite ${ }^{27}$ ) using the model of formatecontaining WT OxDC (PDB 1J58) ${ }^{10 \mathrm{~b}}$ after removal of all ligands. The structure was refined using alternating rounds of manual rebuilding in $\mathrm{COOT}^{28}$ followed by minimization in PHENIX to give a final model that contained residues 6-382 with 4 molecules in the asymmetric unit, 1228 waters, and $8 \mathrm{Co}$ (II) ions. The model was refined to $2.1 \AA$ resolution with a $R_{\text {work }}$ and $R_{\text {free }}$ of 19.6 and $22.7 \%$, respectively (Table 3). The Ramachandran plot shows that $97.6 \%$ of residues fall in the most favored regions with $2.3 \%$ in the allowed regions. The maximum likelihood coordinate error is $0.23 \AA$, consistent with accurate coordinates. Coordinates and structure factors for the $\mathrm{Co}(\mathrm{II})$ containing W132F variant have been deposited in the PDB with accession code 4MET.

EPR Studies of WT OxDC and the W132F OxDC Variant. High-field EPR spectra at $324.6 \mathrm{GHz}$ were recorded at the National High Magnetic Field Laboratory (NHMFL), using a homodyne transmission-mode spectrometer with a nonresonant probe and a $17 \mathrm{~T}$ superconducting magnet. ${ }^{29}$ WT OxDC $(27 \mathrm{mg} / \mathrm{mL} ; 1.4 \mathrm{Mn} /$ monomer) or the W132F OxDC variant $(40 \mathrm{mg} / \mathrm{mL} ; 1.6 \mathrm{Mn} /$ monomer) was dialyzed into $50 \mathrm{mM}$ Tris, $\mathrm{pH} 8.5$, containing $500 \mathrm{mM}$ $\mathrm{NaCl}$. Approximately $200 \mu \mathrm{L}$ of this solution was placed into a Teflon cup with $7.2 \mathrm{~mm}$ i.d. and placed into the FIR beam of the spectrometer at $4 \mathrm{~K}$, as measured using a built-in carbon-glass temperature sensor in the cryostat. A Cernox sensor was used to map out the temperature scale at the sample position to correct for any temperature gradient in the cryostat. Spectra were taken with a modulation amplitude of approximately $27 \mathrm{G}$ at a modulation frequency of $30 \mathrm{kHz}$ using a phase-sensitive lock-in detector with the time constant set to $300 \mathrm{~ms}$. Field scans were taken with a sweep speed of $2 \mathrm{mT} / \mathrm{s}$. The spectra were simulated based on the usual spin Hamiltonian (shown below) using the EasySpin toolbox for Matlab. ${ }^{30}$

$$
\begin{aligned}
\hat{H}= & D\left[\hat{S}_{z} \cdot \hat{S}_{z}-\hat{S}(\hat{S}+1) / 3\right]+E\left(\hat{S}_{x} \cdot \hat{S}_{x}-\hat{S}_{y} \cdot \hat{S}_{y}\right)+g \mu_{\mathrm{B}} B_{\mathrm{o}} \cdot \hat{S} \\
& +a_{\text {iso }} \hat{S} \cdot \hat{I}
\end{aligned}
$$

MD Simulations. MD simulations of the wild-type form of OxDC were based on the 1UW8 crystal structure of the enzyme. Two different procedures were employed to build the W132F OxDC variant: (i) in silico mutation, manually substituting Trp- 132 by Phe in the 1UW8 X-ray structure, and (ii) replacement of Co with Mn using the Co-substituted W132F OxDC mutant as template. In every case, the initial structure was immersed in a periodic box of approximately $77 \times 118 \times 87 \AA^{3}$ containing about 22500 water molecules and neutralized with $\mathrm{Na}^{+}$counterions. The box dimensions were chosen to achieve a minimum distance of $30 \AA$ between two periodically replicated images of the protein. The all-atom AMBER03 force field ${ }^{31}$ was used to model protein residues and ions, whereas the TIP3P model $^{32}$ was employed for water molecules. All potentially charged amino acids, including the $\mathrm{C}$ - and $\mathrm{N}$-termini, were considered to be in their default protonation states at physiological $\mathrm{pH}$ (i.e., charged). Electrostatic interactions were taken into account using the particle mesh Ewald algorithm ${ }^{33}$ with a real space cutoff of $10 \AA$. The same cutoff was employed for the treatment of the van der Waals interactions. Bonds involving hydrogen atoms were constrained using the SHAKE algorithm. ${ }^{34}$ An integration time step of 2 fs was used. Constant temperature $(300 \mathrm{~K})$ and pressure $(1 \mathrm{~atm})$ were achieved by coupling the systems to a Langevin thermostat and a Nosé-Hoover Langevin barostat, respectively. ${ }^{35,36}$ Systems were first minimized using a conjugate gradient algorithm and then heated to $300 \mathrm{~K}$ in 600 ps while keeping positional restraints on protein heavy atoms. For each system, an initial run of $5.4 \mathrm{~ns}$ in the NPT ensemble, slowly removing the restraints, was followed by a subsequent $20 \mathrm{~ns}$ simulation in the canonical (NVT) ensemble in order to provide starting configurations for the subsequent $\mathrm{QM} / \mathrm{MM}$ optimizations. All the classical MD simulations were carried out using the NAMD package. $^{37}$

QM/MM Geometry Optimizations. QM/MM geometry optimizations were performed starting from equilibrated configurations taken from the aforementioned classical runs. The quantum mechanical/molecular mechanical (QM/MM) implementation employed combines the use of the QM program QUICKSTEP ${ }^{38}$ and the MM driver FIST, both part of the CP2K package (freely available at http://cp2k.berlios.de, released under GPL license). In this code, the general $\mathrm{QM} / \mathrm{MM}$ scheme is based on a real-space multigrid technique to compute the electrostatic coupling between both $\mathrm{QM}$ and $\mathrm{MM}$ regions. ${ }^{39,40}$ In all the optimizations, a quantum region consisting of the $\mathrm{Mn}$ center together with the residues at a distance shorter than $6 \AA$ from it (including only the side chains up to the $\mathrm{C}_{\beta}$ atom) was treated at the density functional theory level, whereas the remaining part of the system, including water molecules and counterions, was modeled at the classical level using the AMBER force field to take explicitly into account the steric and electrostatic effects of the surroundings. The valence of the terminal QM atoms was saturated by the addition of capping hydrogen atoms. A dual basis set, Gaussian and plane-wave formalism, was employed to compute the interaction energy within the QM subsystem. A molecularly optimized double- $\zeta$ valence basis set 
augmented with polarization functions (m-DZVP) was used $^{41}$ to describe the wave function, while an auxiliary plane-wave basis set expanded up to a density cutoff of $360 \mathrm{Ry}$ was utilized to converge the electron density in conjunction with Goedecker-Teter-Hutter pseudopotentials ${ }^{42,43}$ to describe the core electrons. Exchange and correlation energies were computed within the generalized gradient approximation by using the BLYP functional. ${ }^{44,45}$

Zero-Field Splitting Calculations. The calculation of the SOC and SS parts of the zfs parameters was performed with the ORCA electronic structure package. ${ }^{46} \mathrm{We}$ performed these calculations on cluster models, in which only the $\mathrm{OH} / \mathrm{H}_{2} \mathrm{O}$ molecules in the active site cavity and the side chains of all the residues in the first coordination sphere around the metal were included. DFT-based zfs parameters were computed for these models using the hybrid B3LYP ${ }^{25}$ functional in conjunction with triple- $\zeta$ (def2-TZVP) valence basis sets, ${ }^{47}$ taking advantage of the RIJCOSX approximation ${ }^{48}$ to speed up the calculations. In all cases, tight SCF convergence criteria were employed. The coupled-perturbed SOC approach was used to evaluate the $D_{\mathrm{SOC}}$ contribution, whereas the $D_{\mathrm{SS}}$ contribution was obtained on the basis of the spin-unrestricted natural orbital determinant. ${ }^{49}$ Scalar relativistic effects were taken into account by means of the van Wüllen's model potential approximation to the ZORA equations. ${ }^{50}$

\section{ASSOCIATED CONTENT}

\section{S Supporting Information}

Tables S1 and S2, Figures S1-S10, EPR simulation parameters, experimental details for the preparation and purification of the W132F OxDC variant, and Cartesian coordinates for all cluster models. This material is available free of charge via the Internet at http://pubs.acs.org.

\section{AUTHOR INFORMATION}

\section{Corresponding Authors}

ursula.roethlisberger@epfl.ch

richards@qtp.ufl.edu

Notes

The authors declare no competing financial interest.

\section{ACKNOWLEDGMENTS}

We thank Dr. Stephen Bornemann (John Innes Center, Norwich, UK) for generously providing a plasmid containing the gene encoding C-terminally $\mathrm{His}_{6}$-tagged Bacillus subtilis $\mathrm{OxDC}$, and for permission to use Figure 3. We acknowledge the invaluable help of Dr. Elizabeth Brunk in the preparation of the TOC graphic. These studies were funded by the National Science Foundation (CHE1213440 to A.A.), the Swiss National Science Foundation (U.R.), and the National Institutes of Health (DK061666 to N.G.J.R.). Beamline X25 is funded by NIH's National Center for Research Resources and DOE's Office of Biological and Environmental Research. The highfield EPR spectra were recorded at the NHMFL, which is funded by the NSF through the Cooperative Agreement No. DMR-1157490, the State of Florida and the DOE.

\section{REFERENCES}

(1) (a) Svedruzic, D.; Jonsson, S.; Toyota, C. G.; Reinhardt, L. A.; Ricagno, S.; Lindqvist, Y.; Richards, N. G. J. Arch. Biochem. Biophys. 2005, 413, 176-192. (b) Tanner, A.; Bornemann, S. J. Bacteriol. 2000, 182, 5271-5273. (c) Mehta, A.; Datta, A. J. Biol. Chem. 1991, 266, 23548-23553. (d) Lillehoj, E. B.; Smith, F. G. Arch. Biochem. Biophys. 1965, 109, 216-220. (e) Emiliani, E.; Bekes, P. Arch. Biochem. Biophys. 1964, 105, 488-493. (f) Shimazono, H.; Haiyashi, O. J. Biol. Chem. 1957, 227, 151-159.

(2) (a) Martin, G.; Guggiari, M.; Bravo, D.; Zopfi, J.; Cailleau, G.; Aragno, M.; Job, D.; Verrecchia, E.; Junier, P. Environ. Microbiol. 2012,
14, 2960-2970. (b) Dunwell, J. M.; Khuri, S.; Gane, P. J. Microbiol. Mol. Biol. Rev. 2000, 64, 153-179.

(3) (a) Costa, T.; Steil, L.; Martins, L. O.; Volker, U.; Henriques, A. O. J. Bacteriol. 2004, 186, 1462-1474. (b) Walz, A.; Zingen-Sell, I.; Theisen, S.; Kortekamp, A. Eur. J. Plant Pathol. 2008, 120, 317-330.

(4) (a) Makela, M. R.; Hilden, K.; Lundell, T. K. Appl. Microbiol. Biotechnol. 2010, 87, 801-814. (b) Cassland, P.; Sjode, A.; Windestrand, S. Appl. Biochem. Biotechnol. 2010, 161, 2655-263.

(5) Wolfenden, R.; Lewis, C. A., Jr.; Yuan, Y. J. Am. Chem. Soc. 2011, 133, 5683-5685.

(6) (a) Reinhardt, L. A.; Svedruzic, D.; Chang, C. H.; Cleland, W. W.; Richards, N. G. J. J. Am. Chem. Soc. 2003, 125, 1244-1252. (b) Svedruzic, D.; Liu, Y.; Reinhardt, L. A.; Wroclawska, E.; Cleland, W. W.; Richards, N. G. J. Arch. Biochem. Biophys. 2007, 464, 36-47.

(7) Imaram, W.; Saylor, B. T.; Centonze, C.; Richards, N. G. J.; Angerhofer, A. Free Radical Biol. Med. 2011, 50, 1009-1015.

(8) (a) Moomaw, E. W.; Angerhofer, A.; Moussatche, P.; Ozarowski, A.; Garcia-Rubio, I.; Richards, N. G. J. Biochemistry 2009, 48, 61166125. (b) Tanner, A.; Bowater, L.; Fairhurst, S. A.; Bornemann, S. J. Biol. Chem. 2001, 276, 14627-14634.

(9) (a) Cox, N.; Ogata, H.; Stolle, P.; Reijerse, E.; Auling, G.; Lubitz, W. J. Am. Chem. Soc. 2010, 132, 11197-11213. (b) Boussac, A.; Sugiura, M.; Rutherford, A. W.; Dorlet, P. J. Am. Chem. Soc. 2009, 131, 5050-5051. (c) Krebs, C.; Matthews, M. L.; Jiang, W.; Bollinger, J. M. Biochemistry 2007, 46, 10413-10418.

(10) (a) Just, V. J.; Stevenson, C. E.; Bowater, L.; Tanner, A.; Lawson, D. M.; Bornemann, S. J. Biol. Chem. 2004, 279, 1986719874. (b) Anand, R.; Dorrestein, P. C.; Kinsland, C.; Begley, T. P.; Ealick, S. E. Biochemistry 2002, 41, 7659-7669. (c) Just, V. J.; Burrell, M. R.; Bowater, L.; McRobbie, I.; Stevenson, C. E. M.; Lawson, D. M.; Bornemann, S. Biochem. J. 2007, 407, 397-408.

(11) Humphrey, W.; Dalke, A.; Schulten, K. J. Mol. Graph. 1996, 14, $33-38$.

(12) (a) Angerhofer, A.; Moomaw, E. W.; Garcia-Rubio, I.; Ozarowski, A.; Krzystek, J.; Weber, R. T.; Richards, N. G. J. J. Phys. Chem. B 2007, 111, 5043-5046. (b) Tabares, L. C.; Gätjens, J.; Hureau, C.; Burrell, M. R.; Bowater, L.; Pecoraro, V. L.; Bornemann, S.; Un, S. J. Phys. Chem. B 2009, 113, 9016-9025.

(13) (a) Duboc, C.; Phoeung, T.; Zein, S.; Pecaut, J.; Collomb, M. N.; Neese, F. Inorg. Chem. 2007, 46, 4905-4916. (b) Duboc, C.; Collomb, M. N.; Neese, F. Appl. Magn. Reson. 2010, 37, 229-245. (c) Rich, J.; Castillo, C. E.; Romero, I.; Rodriguez, M.; Duboc, C.; Collomb, M. N. Eur. J. Inorg. Chem. 2007, 3658-3665.

(14) Carmieli, R.; Larsen, T. M.; Reed, G. H.; Zein, S.; Neese, F.; Goldfarb, D. J. Am. Chem. Soc. 2007, 129, 4240-4252.

(15) Zein, S.; Neese, F. J. Phys. Chem. A 2008, 112, 7976-7983.

(16) Weil, J. A.; Bolton, J. R.; Wertz, J. E. Electron Paramagnetic Resonance-Elementary Theory and Practical Applications; John Wiley \& Sons: New York, 1994.

(17) Un, S.; Tabares, L. C.; Cortez, N.; Hiraoka, B. Y.; Yamakura, F. J. Am. Chem. Soc. 2004, 126, 2720-2726.

(18) Castagnetto, J. M.; Hennessy, S. W.; Roberts, V. A.; Getzoff, E. D.; Tainer, J. A.; Pique, M. E. Nucleic Acids Res. 2002, 30, 379-82.

(19) Saylor, B. T.; Reinhardt, L. A.; Lu, Z.; Shukla, M. S.; Nguyen, L.; Cleland, W. W.; Angerhofer, A.; Allen, K. N.; Richards, N. G. J. Biochemistry 2012, 51, 2911-2920.

(20) Burrell, M. R.; Just, V. J.; Bowater, L.; Fairhurst, S. A.; Requena, L.; Lawson, D. M.; Bornemann, S. Biochemistry 2007, 46, 1232712336.

(21) (a) Duboc, C.; Ganyushin, D.; Sivalingam, K.; Collomb, M. N.; Neese, F. J. Phys. Chem. A 2010, 114, 10750-10758. (b) Neese, F. J. Am. Chem. Soc. 2006, 128, 10213-10222. (c) Sinnecker, S.; Neese, F. J. Phys. Chem. A 2006, 110, 12267-12275.

(22) Becke, A. D. J. Chem. Phys. 1993, 98, 1372-1377.

(23) Bradford, M. M. Analyt. Biochem. 1976, 72, 248-254.

(24) Ho, S. N.; Hunt, H. D.; Horton, R. M.; Pullen, J. K.; Pease, L R. Gene 1989, 77, 51-59.

(25) Cleland, W. W. Methods Enzymol. 1979, 62, 151-160. 
(26) Vagin, A.; Teplakov, A. Acta Crystallogr., Sect. D 2010, 66, 2225.

(27) Adams, P. D.; Afonine, P. V.; Bunkoczj, G.; Chen, V. B.; Davis, I. W.; Echols, N.; Headd, J. J.; Hung, L. W.; Kapral, G. J.; GrosseKunstleve, R. W.; McCoy, A. J.; Moriarty, N. W.; Oeffner, R.; Read, R. J.; Richardson, D. C.; Richardson, J. S.; Terwilliger, T. C.; Zwart, P. H. Acta Crystallogr., Sect. D 2010, 66, 213-221.

(28) Emsley, P.; Cowtan, K. Acta Crystallogr., Sect. D 2004, 60, $2126-2132$.

(29) Hassan, A. K.; Pardi, L. A.; Krzystek, J.; Sienkiewicz, A.; Goy, P.; Rohrer, M.; Brunel, L.-C. J. Magn. Reson. 2000, 142, 300-312.

(30) Stoll, S.; Schweiger, A. J. Magn. Reson. 2006, 178, 42-55.

(31) Duan, Y.; Wu, C.; Chowdhury, S.; Lee, M. C.; Xiong, G.; Zhang, W.; Yang, R.; Cieplak, P.; Luo, R.; Lee, T. J. Comput. Chem. 2003, 24, 1999-2012.

(32) Jorgensen, W. L.; Chandrasekhar, J.; Madura, J. D.; Impey, R. W.; Klein, M. L. J. Comput. Phys. 1983, 79, 926-935.

(33) Essmann, U.; Perera, L.; Berkowitz, M. L.; Darden, T.; Lee, H.; Pedersen, L. G. J. Chem. Phys. 1995, 103, 8577-8593.

(34) Ryckaert, J. P.; Ciccotti, G.; Berendsen, H. J. C. J. Comput. Phys. 1977, 23, 327-341.

(35) Feller, S. E.; Zhang, Y.; Pastor, R. W.; Brooks, B. R. J. Chem. Phys. 1995, 103, 4613-4621.

(36) Martyna, G.; Tobias, D.; Klein, M. J. Chem. Phys. 1994, 101, 4177-4189.

(37) Kalé, L.; Skeel, R.; Bhandarkar, M.; Brunner, R.; Gursoy, A.; Krawetz, N.; Phillips, J.; Shinozaki, A.; Varadarajan, K.; Schulten, K. J. Comput. Phys. 1999, 151, 283-312.

(38) VandeVondele, J.; Krack, M.; Mohamed, F.; Parrinello, M.; Chassaing, T.; Hutter, J. Comput. Phys. Commun. 2005, 167, 103-128.

(39) Laino, T.; Mohamed, A.; Laio, A.; Parrinello, M. J. Chem. Theory Comput. 2005, 1, 1176-1184.

(40) Laio, A.; VandeVondele, J.; Rothlisberger, U. J. Chem. Phys. 2002, 116, 6941-6948.

(41) VandeVondele, J.; Hutter, J. J. Chem. Phys. 2007, 127, 114105114113.

(42) Goedecker, S.; Teter, M.; Hutter, J. Phys. Rev. B 1996, 54, $1703-1710$.

(43) Hartwigsen, C.; Goedecker, S.; Hutter, J. Phys. Rev. B 1998, 58, $3641-3662$.

(44) Becke, A. D. Phys. Rev. A 1988, 38, 3098-3100.

(45) Lee, C.; Yang, W.; Parr, R. G. Phys. Rev. B 1988, 37, 785-789.

(46) Neese, F. ORCA: An Ab Initio, Density Functional and Semiempirical Program Package, version 2.8 (Rev: 2360); University of Bonn: Bonn, Germany, 2011.

(47) Weigend, F.; Ahlrichs, R. Phys. Chem. Chem. Phys. 2005, 7, 3297-3305.

(48) Neese, F.; Wennmohs, F.; Hansen, A.; Becker, U. J. Chem. Phys. 2009, 356, 98-109.

(49) Neese, F. J. Chem. Phys. 2007, 127, 164112.

(50) (a) van Wüllen, C. J. Chem. Phys. 1998, 109, 392-399. (b) van Lenthe, E.; Snijders, J. G.; Baerends, E. J. J. Chem. Phys. 1996, 105, 6505-6516. (c) van Lenthe, E.; Baerends, E. J.; Snijders, J. G. J. Chem. Phys. 1993, 99, 4597-4610. 